\title{
Management of a Giant Sublingual Dermoid: A Case Report
}

\author{
Eapen Thomas, Ravi Rajan, Akhilesh Prathap, Vinesh Udayakumar, Nithin Pratap
}

Department of Oral and Maxillofacial Surgery, Pushpagiri Dental College, Thiruvalla, India

Email address:

dr.ravi.ra@gmail.com (E. Thomas)

\section{To cite this article:}

Eapen Thomas, Ravi Rajan, Akhilesh Prathap, Vinesh Udayakumar, Nithin Pratap. Management of a Giant Sublingual Dermoid: A Case Report. International Journal of Clinical Oral and Maxillofacial Surgery. Vol. 5, No. 1, 2019, pp. 18-21. doi: 10.11648/j.ijcoms.20190501.15

Received: January 14, 2019; Accepted: May 6, 2019; Published: June 4, 2019

\begin{abstract}
Dermoidcyst are usually seen as a slow growing benign painless mass. The treatment of choice for dermoid cysts is surgical enucleation. The most common location in the head and neck region is the external third of the eyebrow. Sublingual location is very rare. They are benign lesions arising from entrapment of epithelial rests during embryogenesis. Due to its malignant potential, understanding about this lesion is very essential. With the help of radiological investigation like MRI the precise location, extension and relationship of the cyst with the surrounding structures can be identified. Here we represent a case of sublingual swelling in a twenty year old female patient who was treated by surgically excision under general anesthesia. To conclude with proper radiological investigation dermoid cyst in the floor of the mouth can be managed by surgical excision.
\end{abstract}

Keywords: Dermoid Cyst, Submentalcyst, Enucleation

\section{Introduction}

Dermoid cyst of the oral cavity represent very rare. It represents rarely in the head and neck region. benign lesions arising from entrapment of epithelial rests during embryogenesis. They are most frequently located in ovaries and testes. Acquired forms are derived from iatrogenic or traumatic inclusion of epithelium and skin appendages. [1] Up to $6.9 \%$ are found in the head and neck and $1.6 \%$ within the oral cavity representing less than $0.01 \%$ of all oral cavity cysts [2]. The floor of the mouth is the second most common site in the head and neck region after the lateral eyebrow.

The occurrence in oral cavity is approximately $1.6 \%$. They usually present early in life as asymptomatic masses with slow and progressive growth. However, they may reach a large size, becoming clinically apparent in adolescents and young adults, with a potential impact on deglutition, speech, and respiration [3]. These cysts in the floor of mouth may develop above or below the mylohyoid muscle, causing a different clinical presentation. The treatment of choice is surgical excision. An intraoral incision may be used for small cysts, but large ones require an extra oral approach which allows better visualization and control [4]. We report a case of dermoid cyst of floor of mouth in a young adult female, which was successfully treated by surgical enucleation.

\section{Case Report}

A twenty year old female patient reported with a chief complaint of painless midline swelling in the floor of mouth since ten years. The swelling gradually increased in size since two months. The swelling appeared spontaneously. No history of trauma was present. She wasthin built with no history of any systemic illness.

On extraoral examination there was diffuse non tenders welling in the neck. There was no movement of swelling with the respiration, deglutition and protrusion of tongue. The swelling was compressible, non translucent, cystic in consistency, nonpulsatile, non reducible, the mass was bimanually palpable and on digital palpation over submental area the swelling protrudes in to the oral cavity overlying skin was normal in colour and texture, temperature was normal, surface was smooth, not fixed to overlying skin, borders were indistinct, no evidence of fluid thrill and impulse on coughing. MRI revealed a well defined cystic lesion noted in the floor of the mouth which is seen displacing the tongue superiorly and posteriorly and the mylohyoid muscle inferiorly and showing homogenous hyperintense signal. (Figure 1) Result suggested of developmental cystic lesion such as dermoid / epidermoid. 


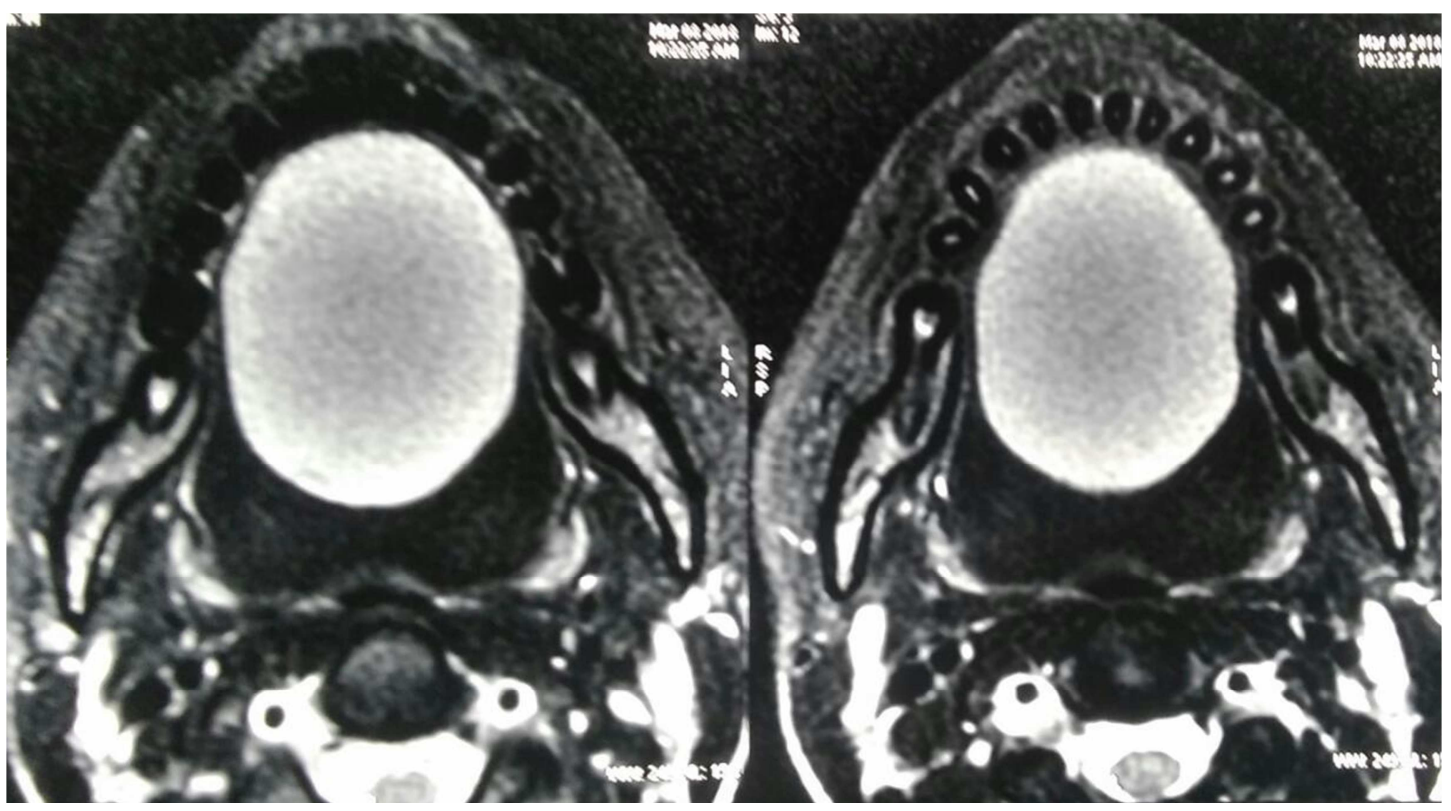

Figuer 1. MRI image of cyst.

All routine laboratory investigations were done which were within normal limits, Surgical excision under general an aesthesia was planned. Nasotracheal intubation was done. (Figure 2).

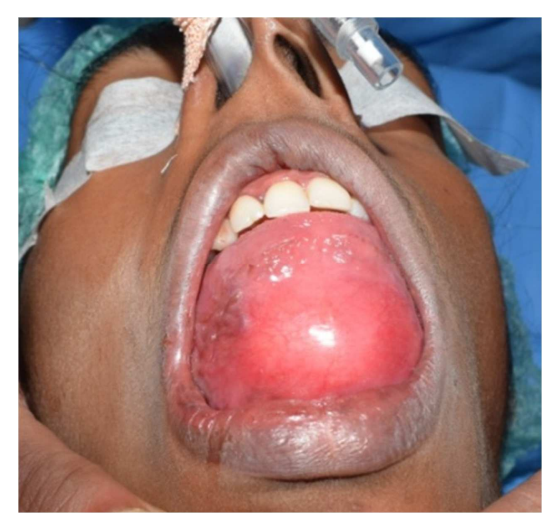

Figure 2. Preoperative image.

An intraoral midline incision from ventral surface of the tongue to the floor of the mouth was used to access the lesion (Figure. 3).

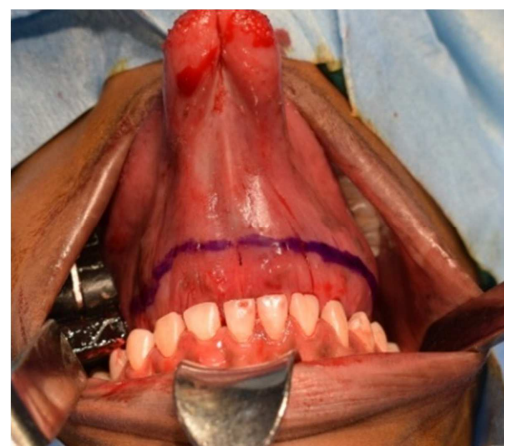

Figure 3. Incision marking.

Special attention was paid to the Wharton's ducts to prevent injury bilaterally. The cyst was completely exposed, and herniation of the cyst through the mylohyoid muscle was seen. A combination of sharp and blunt dissection was used to free the cyst with traction and counter-traction, and it was delivered intact (Figure 4 and 5).

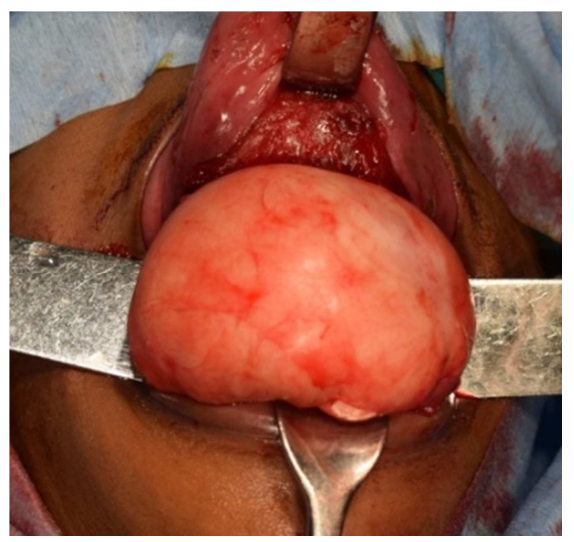

Figure 4. Intraop cyst removal.

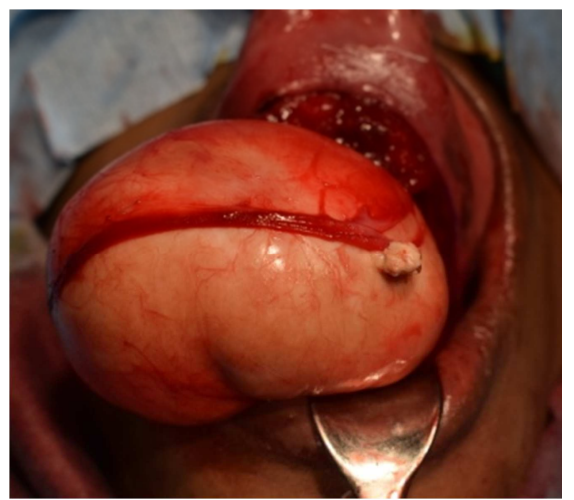

Figure 5. Cyst removed intact.

A dumbell shaped mass full of cheesy material was obtained. The wound was closed in layers using 3-0 vicryl 
(Figure 6 and 7).

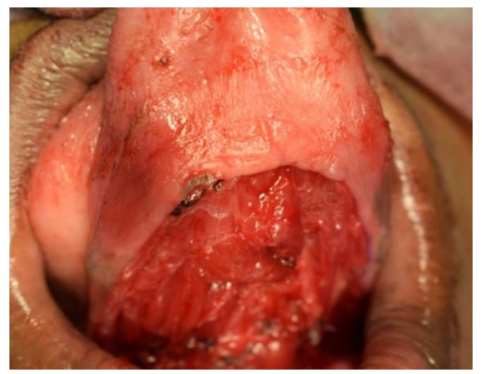

Figure 6. Site after cyst removal.

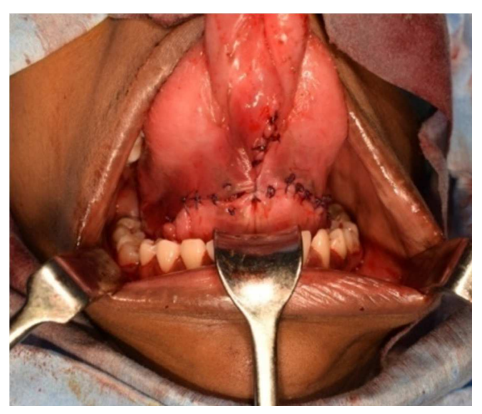

Figure 7. Site closed in layers.

Hematological evaluation revealed a cystic lesion with a stratified squamous epitheliumlining and a fibrovascular connective tissue capsule covering the cystic lumen. These findings are consistent with a dermoidcyst.

\section{Discussion}

Dermoid cysts are congenital, slow growing lesions which is generally seen in young adults during the second and thirddecades of life. Patients usually present with dysphagia, dysphonia, and dyspnea. The cysts in the midline are mainly due to entrapment of ectodermal tissues of first (mandibular) and second (Hyoid) branchial arches, known as dysdontogenic hypothesis or due to traumatic implantation of epithelial cells into deepertissues which suggests traumatic cause [5].

The origin of the dermoid cyst in the floor of mouth is categorized into: congenital and acquired [6]. The widely accepted theory suggest that the cyst results from entrapped midline ectodermal tissue during fusion in the third and fourth weeks in intra uterine life.

The cysts of the midline can be classified according to its relationship to the muscles of the floor of the mouth the cyst of the midlines are classified. Meyer classified the congenital floor of mouth cysts in to three different categories: ectodermal origin, dermoid variant and a teratoid [7, 8].

Sublingual cysts are cysts presenting as swelling in the floor of the mouth which are situated above the mylohyoid and genioglossus muscle. Submental cysts present as a swelling below the chin and is situated between the mylohyoid and geniohyoid muscle [5].

Dermoid cyst may mimic plunging ranula, lipoma, vascular and lymphatic malformation, and salivary gland neoplasm during clinical examination. The size, extent and nature of the lesion can be identified with the help of aids such as ultra sound, magnetic resonance imaging and computed tomography with or without contrast $[9,10]$. CT scan, MRI, Ultrasound, and FNAC can be performed. CT scan and MRI can show the exact location and size of mass and relationship to adjacent structures [10]. MRI help us to identify the cyst and its relationship between geniohyoid and mylohyoidmuscles [11]. Vascular and cystic lesions can be differentiaed with the help of ultrasound imagings. Histopathological study of surgical mass is performed in order to estabilish a final diagnosis. FNAC should be the first line of diagnosticprocedures for lesions presenting in the floor of the mouth [11]. While intraoral incisions are sufficient in accessing mostcases of dermoid occurring in the midline, extraoralincisionsmay be required for cysts occurring inferior to the mylohyiod, in the submandibular regions and for large cystic lesions which extend across the mylohyoid [12]. Lesions that are less than $6 \mathrm{~cm}$ in diameter and above them ylohoid muscle can be managed surgically by intraoral excision and for cysts larger than $6 \mathrm{~cm}$ in diameter should be excised by extraoral approach [11].

Dermoid cyst usually shows a low recurrence rate [12]. Studies by New and Erich have recorded malignant transformation of dermoid cyst but not in the floor of the mouth [13]. Differential diagnosis of cystic lesions of the floor of the mouth is important because the recommended surgical technique is not exactly the samein all of them. Several lesions which can present as acyst orpseudocyst of the floor of the mouth include cystic hygroma, acute infection neuro fibroma, sublingual ranula, lipomas, Ludwig's angina and lymphangioma [14].

Primary management of dermoid cyst comprises total surgical excision and care should be taken not to rupture the cyst, as the contents may act as an irritants to the tissues, causing postoperative inflammation [9].

\section{Conclusion}

Dermoid cysts which are slow growing painless mass are rare in the floor of mouth. Extensive understanding about this is essential because of the symptoms it produces and its malignant potential. When dermoid cysts occur on the floor ofthe mouth, they may enlarge to such an extent that they can interfere with deglutition and can produce respiratory obstruction. Early diagnosis and treatment are essential for these cystic entities. Appropriate imaging techniques is necessary for the diagnosis of cysts of the floor of the mouth. Surgical enucleation is the treatment of choice.

\section{References}

[1] Hemaraju N, Nanda SK, Medikeri SB. Sub-lingual dermoid cyst. Indian Journal of Otolaryngology and Head and Neck Surgery. 2004 Jul 1; 56 (3): 218-20. 
[2] Vieira EM, Borges AH, Volpato LE, Porto AN, Carvalhosa AA, Botelho GD, Bandeca MC. Unusual Dermoid Cyst in Oral Cavity. Case reports in Pathology. 2014 Apr 10; 2014.

[3] W. S. Gibson Jr. and N. A. Fenton, "Congenital SublingualDermoid Cysts," Archives of Otolaryngology—Head \& Neck Surgery, Vol. 108, No. 11, 1982, pp. 745-747.

[4] D. Bloom, D. Carvalho, J. Edmonds, et al., "Neonatal Dermoid Cyst of the Floor of the Mouth Extending to the Midline Neck," Archives of Otolaryngology-Head \& Neck Surgery, Vol. 128, No. 1, 2002, pp. 68-70.

[5] Sheshadri P, Kalappa TM, Krishna BP, Kumaran S, Biddappa ML. Dermoid Cyst of Submental Region Mimicking Pilomatricoma. Journal of Maxillofacial and Oral Surgery. 2015: 1-4.

[6] Taylor BW, Erich JB, Dockerty MB (1966) Dermoids of the head and neck. Minn Med 49: 1535-1540.

[7] Gold BD, Sheinkopf DE, Levy B (1955) Dermoid, epidermoid and teratomatous cysts of the tongue and the floor of the mouth. Journal of Oral Surgery 32: 107-111.

[8] MacNeil SD, Moxham JP (2010) Review of floor of mouth dysontogenic cysts. Ann Oto Rhino Laryngol 119: 165-173.
[9] Longo F, Maremonti P, Mangone GM, DeMaria G, Califano L (2003) Midline (dermoid) cysts of the floor of the mouth: Report of 16 cases and review of surgical techniques. Plast Reconstr Surg 112: 1560-1565.

[10] Kim IK, Kwak HJ, Choi J, Han JY, Park SW (2006) Coexisting sublingual and submental dermoid cysts in an infant. Oral Surg Oral Med Oral Pathol Oral Radio Endod 102: $778-781$

[11] Aydýn S, Demir MG, Demir N, Kayýpmaz PS A Giant Plunging Sublingual Dermoid Cyst Excised by Intraoral Approach J. Maxillofac. Oral Surg. 2016; 15 (2): 277-80.

[12] Cramer H, Lampe H, Downing P. Dermoid cyst of the floor of the mouth diagnosed by fine needle aspiration cytology.. 1996 Jul 1; 40 (2): 319-26.

[13] Gulati U, Mohanty S, Augustine J, Gupta SR. Potentially Fatal Supramylohyoid Sublingual Epidermoid Cyst. Journal of Maxillofacial and Oral Surgery. 2015 Mar 1; 14 (1): 355-9.

[14] Verma S, Kushwaha JK, Sonkar AA, Kumar R, Gupta R. Giant sublingual epidermoid cyst resembling plunging ranula. National Journal of Maxillofacial Surgery. 2012 Jul 1; 3 (2): 211. 